Yasutomo Shinohara - Hironori Iwasaki • Nobutaka Ota

Toshiaki Nakajima • Mina Kodaira - Mitsuko Kajita

Tadayoshi Shiba $\cdot$ Mitsuru Emi

\title{
Novel single nucleotide polymorphisms of the human nuclear factor kappa-B 2 gene identified by sequencing the entire gene
}

Received: October 17, 2000 / Accepted: October 23, 2000

\begin{abstract}
The nuclear factor kappa-B 2 (NFKB2) gene is a member of the NFKB/Rel gene family, which is known to be a pivotal regulator of the acute phase of the inflammatory response and of immune responses. We identified three novel single nucleotide polymorphisms (SNPs) and determined their allelic frequencies, as determined by the sequencing of 48 alleles of the entire gene in a Japanese population sample. Two of the three polymorphisms were identified at nucleotide (nt) position 1837 (T/C) and nt position, $1867(\mathrm{GG} / \mathrm{G})$ in the upstream region of the gene. The other polymorphism was identified at nt position 2584 (G/ $\mathrm{T}$ ) within intron 1 . These polymorphisms will be useful in genetic studies of the processes involved in inflammatory responses and in bone differentiation.
\end{abstract}

Key words Nuclear factor kappa-B - Single nucleotide polymorphism $\cdot$ Japanese population $\cdot$ Inflammation $\cdot$ Bone differentiation

\section{Introduction}

The nuclear factor-kappa B 1 (NFKB1) and NFKB2 genes encode closely related products that regulate immune and inflammatory responses, as well as the differentiation of osteoclasts. NFKB2 is initially synthesized as an approximately $100-\mathrm{kDa}$ protein which needs to be processed in order to bind DNA, either as a homodimer or as a heterodimer with other members of the NF-kappaB/Rel family. The unprocessed form of NFKB2 acts as an

Y. Shinohara $\cdot$ H. Iwasaki $\cdot$ N. Ota $\cdot$ T. Nakajima $\cdot$ M. Kodaira $\cdot$

M. Kajita $\cdot$ M. Emi $(\triangle)$

Department of Molecular Biology, Institute of Gerontology, Nippon Medical School, 1-396 Kosugi-cho, Nakahara-ku, Kawasaki 211-8533, Japan

Tel. +81-44-733-5230; Fax +81-44-733-5192

e-mail:memi@nms.ac.jp

Y. Shinohara $\cdot$ T. Shiba

Department of Molecular Biology, Kitasato University, Sagamihara, Japan
IkappaB-like protein. Therefore, NFKB2 has a dual function. To investigate a possible relationship between genetic variation at the human NFKB2 locus and inflammatory disease, as well as osteoporosis, we searched for single nucleotide polymorphism (SNP)-type sequence variations by sequencing the entire $N F K B 2$ gene in a large panel of Japanese individuals.

\section{Subjects and methods}

Genomic DNA extraction. Blood samples were obtained, with informed consent, from 24 healthy Japanese individuals. Genomic DNA was prepared from each sample.

Polymerase chain reaction (PCR) conditions. PCR and sequencing primers were determined by analyzing the NFKB2 genomic sequence with DNAsis 3.0 software (Hitachi Software Engineering; Tokyo, Japan). The sequencing numbering was adjusted to the RNA transcription start site (A at the top of GenBank U20816.1 is now +1). Five pairs of PCR primers were chosen at approximately 500-bp intervals, with approximately 100-bp overlap. Genomic DNA (10ng) was used as a template for PCR in $10-\mu 1$ reaction volumes containing $10 \mathrm{mM}$ Tris $\mathrm{HCl}(\mathrm{pH} 8.3)$, $1.5 \mathrm{mM} \mathrm{MgCl}_{2}, 50 \mathrm{mM} \mathrm{KCl}, 20 \mathrm{mM}$ each of dNTPs, $1 \mu \mathrm{M}$ each of oligonucleotide primers, and 0.5 U Taq DNA Polymerase (Roche Molecular Biochemicals, Mannheim, Germany), as described previously (Tsukamoto et al. 1998). PCR amplification was performed with a Gene Amp PCR 9600 System (Perkin Elmer Cetus, Norwalk, CT, USA) under the following conditions: $94^{\circ} \mathrm{C}$ for $3 \mathrm{~min}$ and $72^{\circ} \mathrm{C}$ for $3 \mathrm{~min}$; then 5 cycles of $94^{\circ} \mathrm{C}$ for $30 \mathrm{~s}, 60^{\circ} \mathrm{C}$ for $30 \mathrm{~s}$, and $72^{\circ} \mathrm{C}$ for $30 \mathrm{~s}$; and 25 cycles of $94^{\circ} \mathrm{C}$ for $30 \mathrm{~s}, 58^{\circ} \mathrm{C}$ for $30 \mathrm{~s}$, and $72^{\circ} \mathrm{C}$ for $30 \mathrm{~s}$.

DNA sequencing. After purification using DNA-affinity membranes, PCR products were subjected to cycle sequencing with the appropriate primer, as described previously (Tsukamoto and Emi 1998). All sequencing reactions 
Table 1. Novel polymorphisms in the human $N F K B 2$ gene in the Japanese population

\begin{tabular}{llll}
\hline Gene region & Position & Nomenclature & Frequency \\
\hline Upstream of exon 1 & 1837 & $1837 \mathrm{~T} / \mathrm{C}$ & $\mathrm{T}(0.97), \mathrm{C}(0.03)$ \\
Upstream of exon 1 & 1867 & $1867 \mathrm{GG} / \mathrm{G}$ & $\mathrm{GG}(0.50), \mathrm{G}(0.50)$ \\
Intron 1 & 2584 & $2584 \mathrm{G} / \mathrm{T}$ & $\mathrm{G}(0.98), \mathrm{T}(0.02)$ \\
\hline
\end{tabular}

were performed using the $\mathrm{ABI}$ dye terminator cycle sequencing reaction kit (PE Biosystems, Tokyo, Japan). Sequencing samples were then resuspended in formamide and separated on an ABI 377 sequencer (PE Biosystems) and analyzed with attached sequencing software. Differences of sequences in the 24 samples were regarded as SNPs.

\section{Results and discussion}

A total of 24 Japanese individuals were genotyped for sequence variations of the entire NFKB2 structural gene. A total of three SNPs were found in the gene by this method, as shown in Table 1. The location of these SNPs in relation to the genomic structure of the NFKB2 gene is shown in Fig. 1. Of the three SNPs found in the NFKB2 gene, two were located within the upstream region from the first exon, i.e., a T/C at nucleotide (nt) position 1837, and a GG/G at nt position 1867. The other SNP was found in the first intron, i.e., a G/T substitution at nt position 2584. Table 1 shows a summary of the allele frequencies of the novel SNPs determined in the 24 Japanese individuals, consisting of 48 alleles.

Recently, it was reported that the generation of NFKB1 null mice (p50-/-) resulted in altered immune responses, but had no effect on development. Similarly, NFKB2 knockout mice (p52-/-) alone did not show developmental defects either (Iotsova et al. 1997). However, in double NFKB1 and $N F K B 2$ knockout mice, it was shown that these animals developed osteopetrosis because of a defect in osteoclast differentiation (Iotsova et al. 1997). These data suggest that NFKB1 and NFKB2 are candidate genes involved in osteoclast differentiation and, thus, in the regulation of bone mineral density in humans.

In conclusion, these polymorphisms will be useful for the investigation of a possible relationship between genetic variation at the human NFKB2 locus and human diseases, especially in association studies between specific polymorphisms and susceptibility to inflammatory diseases and osteoporosis.

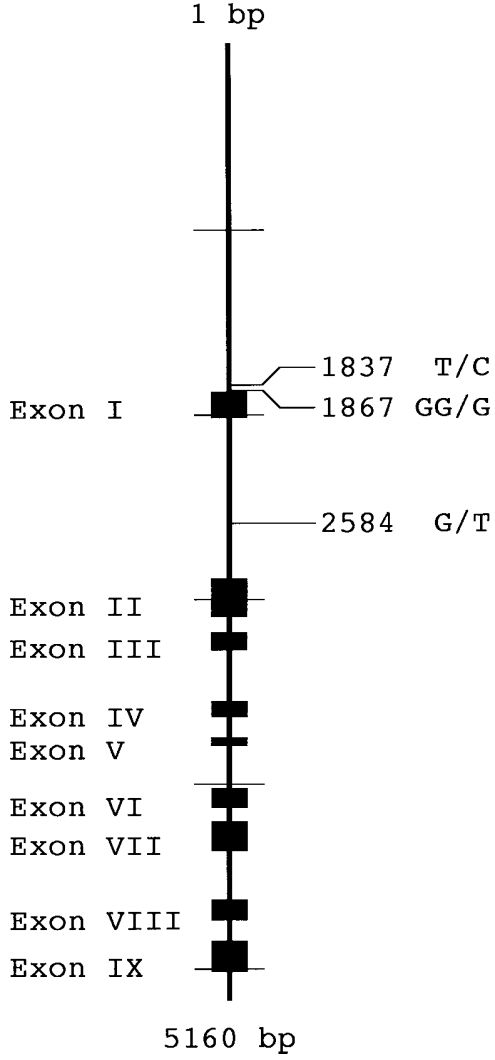

Fig. 1. Genomic structure and location of single nucleotide polymorphisms (SNPs) in the human NFKB2 gene

Acknowledgements This work was supported in part by a special Grant for Strategic Advanced Research on "Cancer" and "Genome Science" from the Ministry of Education, Science, Sports, and Culture of Japan; by a Research Grant from the Ministry of Health and Welfare of Japan; and by a Research for the Future Program Grant of The Japan Society for the Promotion of Science.

\section{References}

Iotsova V, Caamano J, Loy J, Yang Y, Lewin A, Bravo R (1997) Osteopetrosis in mice lacking NF-kappaB1 and NF-kappaB2. Nat Med 3:1285-1289

Tsukamoto K, Haruta K, Shiba T, Emi M (1998) Isolation and mapping of a polymorphic CA repeat sequence at the human interleukin 6 locus. J Hum Genet 43:71-72

Tsukamoto K, Emi M (1998) A polymorphic CA repeat sequence at the human calcitonin locus. J Hum Genet 43:146-147 